\title{
Laboreal
}

Volume $2 \mathrm{~N}^{\circ} 2$ | 2006

Varia

\section{Sobre a Psicologia Ergonómica de Jacques Leplat}

Sobre la Psicología Ergonómica de Jacques Leplat

Sur la Psychologie Ergonomique de Jacques Leplat

About the Ergonomic Psychology of Jacques Leplat

\section{Catarina Silva}

\section{OpenEdition}

\section{Journals}

\section{Edição electrónica}

URL: http://journals.openedition.org/laboreal/13298

DOI: 10.4000/laboreal.13298

ISSN: 1646-5237

\section{Editora}

Universidade do Porto

\section{Refêrencia eletrónica}

Catarina Silva, « Sobre a Psicologia Ergonómica de Jacques Leplat », Laboreal [Online], Volume 2 №2 2006, posto online no dia 01 dezembro 2006, consultado o 10 dezembro 2020. URL : http:// journals.openedition.org/laboreal/13298; DOI : https://doi.org/10.4000/laboreal.13298

Este documento foi criado de forma automática no dia 10 dezembro 2020

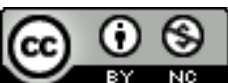

Laboreal está licenciado com uma Licença Creative Commons - Atribuição-NãoComercial 4.0 Internacional. 


\title{
Sobre a Psicologia Ergonómica de Jacques Leplat
}

\author{
Sobre la Psicología Ergonómica de Jacques Leplat \\ Sur la Psychologie Ergonomique de Jacques Leplat \\ About the Ergonomic Psychology of Jacques Leplat
}

\section{Catarina Silva}

\section{NOTA DO EDITOR}

Manuscrito recebido em : Setembro/2006

Aceite após peritagem em : Novembro/2006

\section{Uma pequena história na história de Jacques Leplat}

1 O Professor Jacques Leplat constitui uma referência incontornável na comunidade científica de psicologia do trabalho e de ergonomia e cujo reconhecimento do contributo da sua obra, para o desenvolvimento e afirmação científica daqueles domínios, se estende muito para além da comunidade a que pertence, a francófona. A obra de Leplat é numerosa, abrange diversos campos dentro da psicologia do trabalho e da ergonomia e estendese por um período já longo. Meio século de produção bibliográfica dificulta-nos não só o alcance do enquadramento dos seus textos, como também a obtenção das suas publicações originais para realizar um trabalho de síntese. Reconhecendo essa dificuldade mas também a pertinência, a utilidade e mesmo a actualidade de muitos desses textos, o próprio Jacques Leplat viabiliza a sua acessibilidade aos leitores, primeiramente numa publicação colectiva em dois volumes, da qual é coordenador,

2 “L'analyse du travail en psychologie ergonomique » (1992-3) onde surgem vários textos com a sua assinatura (Leplat, 197172 ; 1985a ; 1986 ; Leplat \& Bisseret 1965 ; Leplat \& 
Hoc 1983), posteriormente reúne um conjunto de outros textos, exclusivamente da sua autoria e republica-os na obra “Regards sur l'activité en situation de travail. Contribution à la psychologie ergonomique » (1997). Mais recentemente decide retomar todos esses seus escritos anteriores, que são considerados hoje referências clássicas não só no domínio da psicologia ergonómica mas também da ergonomia, juntando-lhes trabalhos mais recentes não só do próprio Leplat mas de outros autores igualmente reconhecidos e publicar um livro original “L'analyse psychologique de l'activité en ergonomie. Aperçu sur son évolution, ses modèles et ses méthodes » (2000).

Ao material acima referido, ao qual tivemos acesso, juntámos artigos publicados em periódicos e outras publicações mais antigas com a assinatura de Leplat, nomeadamente os livros “La psychologie ergonomique " (1980) e “Introdução à psicologia do trabalho» (1983), este último publicado originalmente em 1976 em colaboração com Xavier Cuny.

Muitos assuntos publicados por Leplat, de inegável relevância, não serão tratados neste artigo. São exemplos as publicações individuais ou em colaboração no domínio da fiabilidade e da análise de erros e de acidentes $(1985 ; 1989 ; 1990 ; 1993$; 1996 ; 2003 ; Leplat \& Cuny 1979; Leplat \& Terssac, 1990 ; Rasmussen, Duncan \& Leplat, 1987) da formação e da aquisição de habilidades e de competências $(1988$; 1990a ; 1991 ; 1992 ; 1995 ; 2000a ; 2002), da dimensão colectiva do trabalho (1991a, 1993a, 1994, Leplat \& Savoyant 1984), e as reflexões em torno do estatuto da própria psicologia do trabalho, levantando a esse propósito numerosas questões nas práticas metodológicas (1978; 1982 ; $1982 a$;1997 ; 2000) Mas esta redução impunha-se e estamos de acordo com o autor quando, na sua última publicação, utiliza a expressão “ aperçu », que podemos traduzir para português por " resumo ", " relance ", " apanhado ». É isso que vamos procurar fazer nas páginas que seguem, centrando-nos no essencial das ideias apresentadas por Leplat em torno da análise psicológica da actividade.

5 No texto que se segue o leitor encontrará referências bibliográficas de outros autores, quase exclusivamente francófonos, aos quais Leplat faz, de uma forma sistemática, alusão nas suas obras. Embora se trate de uma síntese das ideias de Leplat, e à priori o aparecimento destas referências bibliográficas possa parecer estranho, tornou-se inevitável a sua inclusão em virtude do suporte e coerência que elas dão às ideias do próprio Leplat.

\section{Alicerces da psicologia ergonómica}

\subsection{Origem, conceito e relações com a ergonomia}

6 Encontramos na obra de Leplat “ La psychologie ergonomique » (1980), provavelmente, a primeira tentativa de sistematização de uma concepção de relações entre a ergonomia e a psicologia. $\mathrm{Na}$ introdução, o autor começou precisamente por reconhecer que aquele título não era comum e poderia mesmo surpreender os leitores. Mas acrescentou que o mérito da expressão era de ser breve, uma vez que preferiria designar a obra de "Psychologie du travail en ergonomie", mais explícito em relação ao objecto de estudo. Aliás, foi este o título dado pelo autor, alguns anos antes (1972), ao texto que constitui o seu contributo na obra colectiva dirigida por Reuchlin. De qualquer forma não deixou de se questionar "Não falamos nós de psicologia pedagógica, de psicologia médica, de 
psicologia patológica, porque não de psicologia ergonómica? Designaremos assim o campo da psicologia que está em relação com a ergonomia" (p.5, tradução livre).

7 Não obstante estas considerações o que é facto é que Leplat recentemente retoma a expressão colocando-a em títulos de duas obras "L'analyse du travail en psychologie ergonomique" (tomo 1 e 2, 1992-3) e "Regards sur l'activité en situation de travail. Contribution à la psychologie ergonomique » (1997).

8 Vejamos então o que é que Leplat queria dizer com a expressão “o campo da psicologia que está em relação com a ergonomia ». A ergonomia era entendida pelo autor como uma “(...) tecnologia cujo o objecto é o arranjo dos sistemas homem-máquina, ou mais geralmente das condições de trabalho, em função de critérios cujos mais importantes caracterizam o bem-estar dos trabalhadores (saúde, segurança, satisfação, conforto, etc.)." (1980, p. 6, tradução livre).

9 A psicologia ergonómica é constituída pelo conjunto de conhecimentos psicológicos pertinentes à análise e à solução dos problemas ergonómicos. Estes conhecimentos são resultantes de trabalhos conduzidos no quadro da própria psicologia ergonómica, mas também da psicologia em geral. Eles cobrem campos diversos : percepção, sensóriomotricidade, resolução de problemas, decisão, aprendizagem, psico-semiologia, personalidade, etc. (1980 p.6, tradução livre).

10 Portanto, na opinião de Leplat, a ergonomia constituía um dos campos onde a psicologia podia e devia intervir. Este campo fazia parte, a par com outros, do domínio de intervenção da psicologia do trabalho :

11 A psicologia do trabalho, sector da psicologia, tem por objecto geral o estudo das condutas do Homem no trabalho: ela inclui pois a psicologia ergonómica ao mesmo tempo que a ultrapassa. Com efeito, a ergonomia não é senão um dos campos de intervenção da psicologia do trabalho: entre outros citamos a formação, o recrutamento, a avaliação do trabalho, etc. (1980, p. 7, tradução livre). Dezassete anos depois Leplat (1997) apresenta uma nova concepção da relação entre a psicologia e a ergonomia cujo aspecto essencial, do nosso ponto de vista, é a consideração explícita da ergonomia como disciplina e consequentemente o abandono da ideia de encará-la apenas como campo de aplicação de diversas ciências, entre as quais da própria psicologia. "(...) nós consideramos a ergonomia como uma tecnologia [1], quer dizer como disciplina que visa transformar o trabalho (...)" (p. 3, tradução livre) Neste enquadramento, "a psicologia ergonómica cobre os conhecimentos de psicologia susceptíveis de contribuir para a ergonomia, para o desenvolvimento dos seus conhecimentos e das suas intervenções, quer dizer para a análise e para a solução de problemas ergonómicos." (p.3, tradução livre).

12 É claro que esta nova concepção da psicologia ergonómica não está desligada da evolução das concepções relativas ao estatuto científico da própria ergonomia, o qual tem sido objecto de debate nos últimos anos (Daniellou, 1996; Dessaigne \& Gaillard, 1997 ; SELF, 1997).

13 Neste novo quadro de relações Leplat $(1997 ; 2000)$ situa a especificidade, mas também o contributo, da análise psicológica da actividade na abordagem ergonómica. 


\subsection{Análise psicológica da actividade e análise ergonómica do trabalho.}

Em variados textos, Leplat $(1986 ; 1993 b ; 1997 ; 2000)$ procura distinguir a análise psicológica do trabalho da análise ergonómica do trabalho.

(...) a análise psicológica do trabalho" não é sinónimo de "análise ergonómica do trabalho ». A análise psicológica visa essencialmente analisar os mecanismos da actividade postos em jogo em situação de trabalho. A análise ergonómica, visa analisar a situação de trabalho com vista a transformá-la, e a psicologia não é mais que uma das suas dimensões, não necessariamente a principal. (Leplat, 1993b, p. 121, tradução livre).

Esta distinção reenvia para as relações atrás referidas entre a própria psicologia e a ergonomia.

Nesta concepção, Leplat vê com toda a vantagem a conjugação da análise psicológica do trabalho com análises que se ocupem de outras dimensões (fisiológica, semiológica, sociológica, etc.,) concorrendo com elas para um melhor conhecimento das diversas facetas que caracterizam as situações de trabalho (Leplat, 1993b). É por isso que, por diversas vezes, Leplat se refere à expressão de Dadoy (1990) " análises do trabalho " (note-se no plural), precisamente para ilustrar a multiplicidade de análises possíveis de se realizarem sobre as situações de trabalho.

17 Apesar da clareza das distinções apresentadas, o que é facto é que para ambas as análises, psicológica e ergonómica, a actividade do homem em situação de trabalho surge como objecto de pesquisa. Vejamos alguns exemplos. Em ergonomia, Wisner (1995) afirma-nos que "a parte central e original da análise ergonómica do trabalho é a análise da actividade" (p. 132, tradução livre) ; Guérin et al. (1991) falam de “(...) ergonomia centrada sobre a análise da actividade(...)" (p.16, tradução livre). Por seu turno, é o próprio Leplat (1997) que afirma que "para a psicologia, o trabalho é considerado como uma actividade." (p.4, tradução livre) ; e mais adiante que “(...) a análise psicológica do trabalho é a da actividade em situação de trabalho" (p.13, tradução livre).

Mas é óbvio que o desenrolar da história deixou as suas marcas na relação que se acabou por estabelecer entre estas duas análises (Leplat, 1993b). Leplat (2000) lembra que os primeiros trabalhos consagrados à análise da actividade tiveram origem nas abordagens dos psicólogos Lahy e Pacaud no início do século passado, em França: os seus trabalhos, orientados para a selecção profissional, abriram-se progressivamente para preocupações mais directamente relacionadas com as condições de trabalho (Clot, 1996). Mais tarde, Ombredane e Faverge, também psicólogos do trabalho, tiveram um contributo essencial, assumido já na obra “L'analyse du travail » (1955), a distinção, hoje paradigmática, entre trabalho prescrito e trabalho real. É no âmbito desta tradição científica que o próprio Leplat deu, a partir daquela data, uma contribuição relevante : primeiro, no âmbito das investigações conduzidas, nomeadamente com Faverge (de quem foi colaborador de 1953 a 1958), no CERP (Centre d'Etudes et de Recherches Psychotechniques, mais tarde Psychologiques); e mais tarde, na EPHE (Ecole Pratique des Hautes Etudes), na qual foi director do Laboratoire de Psychologie du Travail de 1967 a 1989. 
19 A focalização na actividade de trabalho como objecto de estudo surge então pela mão de psicólogos cujos contributos das suas análises emprestados à ergonomia acabam por conduzir a que esta adoptasse também o ponto de vista da actividade. Assim, encontramos hoje documentadas numerosas pesquisas em psicologia que ao colocarem a tónica no carácter situado da actividade são conduzidas a considerar cada vez mais as condições externas, o contexto de trabalho e deste ponto de vista quase se fundem com as análises ergonómicas do trabalho. Reciprocamente, também encontramos pesquisas em ergonomia centradas nos mecanismos psicológicos da actividade e que por isso poderiam muito bem ser consideradas análises psicológicas (mas numa versão aplicada) (Leplat 2000).

20 Então, coloca-se a questão : o que é que distingue efectivamente estas duas análises ? Leplat responde a esta questão da seguinte forma :

21 Notamos somente que no estudo das condições da actividade, o psicólogo, como tal, é talvez mais centrado sobre a organização da actividade que sobre as próprias condições. Mas, em ambos os casos, o ponto de vista interactivo é prioritário : é a ligação dinâmica das condições internas e externas da actividade que é a chave da compreensão dessa última. O ergonomista não pode encontrar a fonte da sua especificidade no facto de se interessar pelas condições externas da actividade, do mesmo modo que o psicólogo não pode encontrar a fonte da sua especificidade no interesse que dá ao operador. Com efeito, as condições externas não são um objecto pertinente de análise para o ergonomista senão na medida em que este pode mostrar que elas condicionam efectivamente a actividade do operador. Inversamente, a atenção dada ao operador e às suas características não é pertinente senão na medida em que estas têm uma ligação com a actividade na situação em que se encontra o operador (Leplat 2000, p. 5, tradução livre).

22 Num outro texto acrescenta: "Ela (análise psicológica) junta-se então à análise ergonómica, distinguindo-se, contudo pelo facto de que não visa a transformação das situações. Mas, a psicologia ergonómica, como a psicologia do trabalho, pode ter uma vertente aplicada e, então, torna-se uma componente da ergonomia." (1997, p. 4, tradução livre).

\subsection{Construção de um modelo-guia para a análise}

O modelo-guia para a análise psicológica que Leplat (2000) nos apresenta, resulta de uma continuada reflexão do autor, cujas origens situamos na obra publicada com Cuny (1983). Outras obras (Leplat 1980 ; Leplat \& Hoc 1983) vieram reforçar e precisar melhor as ideias iniciais. A figura 1 (cf. no final do artigo), constitui uma apresentação esquemática do modelo.

24 O modelo é fundado sobre a ideia, já anteriormente exposta, de que para a psicologia ergonómica o trabalho é uma actividade. Esta actividade é concebida como sendo determinada por condições internas e externas e pela sua ligação. Leplat (2000) faz questão de alertar que o funcionamento do modelo, como veremos adiante, é essencialmente dinâmico, o que torna difícil qualquer divisão para fins de análise e convida a precisar para toda a análise escolhida, forçosamente redutora, os seus fundamentos e limites. Na figura salientam-se os três níveis de análise a articular: condições da actividade, actividade propriamente dita e consequências da actividade. As setas ilustram as articulações possíveis entre os diferentes elementos do modelo. 
Figura 1 Esquema geral para a análise da actividade.

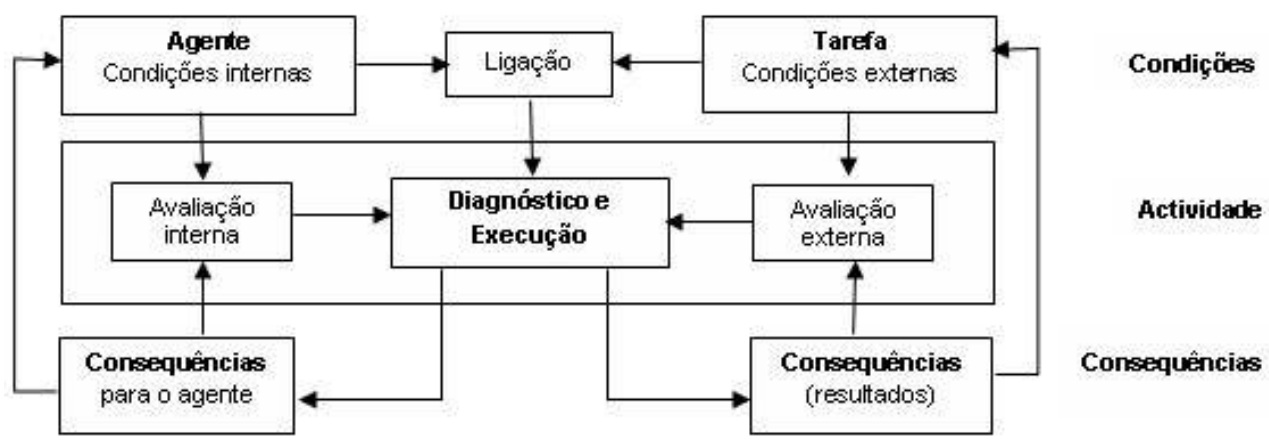

A actividade depende do operador (condições internas) que a executa e da tarefa (objectivo(s), condições externas : técnicas, organizacionais, sociais, etc.). A tarefa e seu operador analisam-se conjuntamente pelas características da sua ligação. As consequências da actividade agem retroactivamente sobre a própria actividade, em função da sua adequação aos objectivos perseguidos pelo operador, de um lado, fixados pela tarefa, por outro. Estes dois tipos de circuitos de regulação (interno e externo) dão um caracter dinâmico a toda a actividade. Ler a --> b como " $b$ depende de a » (in Leplat 2000, p. 11).

\subsubsection{As condições externas}

As condições externas são frequentemente designadas por tarefa. Este conceito não foi logo adoptado na história da análise psicológica do trabalho. Na obra "Introdução à psicologia do trabalho", Leplat e Cuny (1983) adoptam a expressão exigências do trabalho, dando continuidade às ideias apresentadas por Ombredane e Faverge (1955). É na sua obra "La psychologie ergonomique " (1980) que Leplat apresenta formalmente a expressão "condições de trabalho", dividindo-as em externas e internas e considerando-as como um nível de análise do trabalho. Posteriormente, é preferido o conceito de tarefa ao de condições (estas serão tidas, como veremos, por elementos a considerar na tarefa) e é trabalhada a sua relação com o conceito de actividade de trabalho (Leplat \& Hoc 1983). Este conceito de tarefa acaba por ser aceite e largamente utilizado pela comunidade francófona de psicologia ergonómica e de ergonomia.

A tarefa é concebida por quem comanda a execução e não por quem a executa. Neste sentido, ela pré-existe à actividade, visando orientá-la e determina-la de maneira mais ou menos completa. Leplat e Hoc (1983) definem a tarefa como,

(...) num objectivo dado em condições determinadas. (...) o objectivo é o que deve ser realizado ou mais precisamente o estado final. (...) o objectivo deve ser atingido em certas condições exprimíveis segundo um ou outro de três pontos de vista : (1) o dos estados a percorrer antes de atingir o estado final que constitui o objectivo; (2) o das operações admissíveis para percorrer esses estados; (3) o do procedimento a por em prática para o fazer, quer dizer a combinação dessas operações (p.48, tradução livre).

Poderão existir vários objectivos (produção, qualidade, segurança, etc.) definidos com maior ou menor precisão. Segundo Leplat (2000), o grau de explicitação útil do objectivo depende da competência do operador, da autonomia que lhe é deixada e do carácter mais ou menos processual da tarefa. Com efeito, podem ocorrer situações em 
que o objectivo pode estar bem definido para aquele que concebeu a tarefa, sem o estar para o operador que a realiza.

Leplat $(1980,2000)$ considera vários tipos de condições : (1) físicas relativas ambiente ou envolvimento de trabalho (ruído, iluminação, vibrações, etc.) ; (2) técnicas relativas ao regime de funcionamento das ferramentas, instrumentos e máquinas; (3) organizacionais relativas às regras que definem a divisão das tarefas, a organização temporal (cadências, horários, etc.), os modos de controlo e de comando, etc. ; (4) sócioeconómicas próprias à sociedade global mais ou menos moduladas pela instituição : repartição de poderes, relações de força sociais.

31 À semelhança do objectivo, as condições devem também ser precisadas. Quando tal não acontece, ou face a uma definição incorrecta, o operador pode ver-se obrigado, para suportar esta ausência ou incorrecção, a adquirir os conhecimentos necessários por formação, pelo recurso a ajudas ou por ensaios e erros.

No caso, em que a definição do trabalho a executar é muito vaga, não se fala mais de tarefa, mas antes de missão do operador.

\subsubsection{As condições internas}

Consiste em identificar as características próprias do operador que são postas em prática no decurso da actividade de trabalho. Leplat $(1997 ; 2000)$ distingue duas grandes categorias de condições internas :

- As características que entram directamente em jogo para a execução da tarefa : traços físicos (altura, acuidade visual, auditiva, idade, etc.), competências, recursos (com o seu aspecto negativo, carga de trabalho, fadiga, etc.), personalidade, confiança no sistema, etc.;

- As características relativas aos próprios fins perseguidos pelo operador. Com efeito, o operador, não procura somente realizar a tarefa prescrita, mas ao mesmo tempo realizar os seus próprios fins, valorizar-se, adquirir um certo estatuto, ser reconhecido pelos seus pares, exprimir certos valores.

As condições internas foram durante muito tempo o objecto principal das pesquisas conduzidas no âmbito da psicologia ergonómica.

Os estudos propriamente psicológicos em meio de trabalha datam do início do século. (...), eles acordaram mais atenção às condições da actividade internas ao indivíduo que às condições externas. Os problemas de recrutamento e de formação orientaram grande parte dos trabalhos de pesquisa e de aplicação. A avaliação das aptidões e das capacidades graças ao aperfeiçoamento dos métodos de teste, ocupou durante muito tempo o essencial da actividade dos psicólogos do trabalho. (Leplat, 1980, p. 14, tradução livre).

Porém, como refere ainda o autor (Leplat, 2000), "esta componente da actividade em situação de trabalho foi durante muito tempo negligenciada em ergonomia, onde a actividade era exclusivamente concebida como resposta à tarefa e como se a finalidade fosse somente fixada por esta última." (p. 13, tradução livre). Portanto, a análise destas características não é clássica, tal como é a da tarefa e a da actividade. O próprio Leplat (1991) a propósito do conceito de competência avançou com esta constatação: "a competência é uma característica do indivíduo e a ergonomia interessa-se mais directamente pelas condições externas do trabalho, a sua compatibilidade em relação ao indivíduo. (...) Porquê pois introduzir este conceito em ergonomia e que benefício se atinge com esta introdução ?" (p. 263, tradução livre). A resposta a esta questão foi-nos 
dada de uma forma clara por Montmollin (1986), e que podemos estender a outras características do operador, que não só a competência, embora a sua resposta esteja para aí orientada: o conceito de competência “(...) surge-nos progressivamente indispensável para explicar, e não somente para descrever, as condutas dos operadores que são produzidas de maneira aleatória e imprevisível, mas assinalam claramente o que cada um sabe : os trabalhadores são pessoas reais e coerentes, com uma experiência e uma memória." (p.121, tradução livre). Portanto, a análise destas características visa contribuir para a descrição e para a explicação da actividade de trabalho e não para a avaliação dos operadores. Esta última constitui uma prática enraizada da psicologia diferencial, da qual a ergonomia ao querer distanciar-se acabou por negligenciar aspectos fundamentais para a sua abordagem.

\subsubsection{A actividade}

A distinção entre tarefa e actividade surge relativamente cedo nas análises do trabalho. Ombredane (1955) defende a ideia da necessidade de se distinguir numa análise do trabalho duas perspectivas :

Duas perspectivas devem distinguir-se desde o início de uma análise do trabalho : a do Quê e a do Como. O que é que há para fazer e como é que os operadores o fazem ? Por um lado, a perspectiva das exigências da tarefa e, por outro, a das atitudes e sequências operacionais pelas quais os indivíduos observados respondem realmente a essas exigências (Ombredade, 1955, p. 2, tradução livre).

39 Esta distinção é mantida por Leplat e Cuny (1983) tomando as " atitudes e sequências operacionais » a designação de “ comportamentos ». Porém esta expressão era reduzida para abarcar o sentido que se lhe pretendia dar. Assim, no livro "La psychologie ergonomique " Leplat (1980) substitui a expressão “comportamento» pela de “ actividade ». Algum tempo depois Leplat, no texto em colaboração com Hoc (1983), trabalha não só o conceito como também a sua relação com a tarefa de uma forma mais aprofundada. Desde Ombredane e Faverge até aos nossos dias, a distinção tarefaactividade tem sido retrabalhada e enriquecida por numerosos autores quer da psicologia quer da ergonomia.

A actividade é a resposta do operador ao conjunto destas condições : é o que o homem faz para realizar a tarefa prescrita ao mesmo tempo que as suas próprias finalidades. Os objectivos e condições definidas pela tarefa prescrita podem também ser redefinidos em função dessas finalidades (Leplat, 2000, p. 13, tradução livre).

Vários autores têm insistido na clarificação da ideia de que a actividade não se resume a comportamentos. Montmollin (1995) diz “(...) a actividade não é o comportamento, mas o processo pelo qual o comportamento é gerado" e, neste sentido a actividade "pode ser puramente mental ou comportar, também, elementos motores observáveis." (p.18, tradução livre).

Os operadores comprometidos na realização de um trabalho apresentam comportamentos observáveis Estes comportamentos são a expressão de uma actividade mental subjacente baseada na situação, nas competências dos operadores e no seu comprometimento na acção, para desempenhar essa tarefa, num preciso momento. 0 conjunto desses comportamentos observáveis e dos conhecimentos e mecanismos mentais, que presidem a sua elaboração e controlo, constitui o que se designa por actividade do sujeito (Amalberti, 1991, p. 19, tradução livre). 
Segundo Leplat (2000),

A actividade pode aplicar-se, por um lado, ao próprio corpo ou a objectos materiais, por outro, às representações. No primeiro caso, falaremos de actividade física ou manual e essa actividade será observável : esta parte visível da actividade define o comportamento. No segundo caso, falaremos de actividade representativa ou mental (ou ainda cognitiva ou intelectual) : a actividade será então inobservável e deverá ser inferida a partir do comportamento e de diversos traços (p.13, tradução livre). considerar que o conceito de actividade não se aplica exclusivamente a comportamentos observáveis na medida em subentende dois componentes, não mutuamente exclusivos e de predominância variável segundo a natureza do trabalho.

\subsubsection{As consequências da actividade}

A compreensão da actividade de trabalho ficará incompleta se não a relacionarmos com o terceiro nível de análise : as consequências da actividade. A actividade de trabalho e as condições nas quais é realizada têm consequências múltiplas sobre a produção e meios de trabalho, bem como sobre os operadores que a realizam.

As consequências sobre o sistema produtivo traduzem-se no grau de afastamento dos resultados em relação aos objectivos definidos pela empresa. Este indicador reveste-se de grande importância uma vez que reflecte, indirectamente, o grau de adaptação do operador às condições externas. São indicadores a este nível, os qualitativos e quantitativos da produção, os erros, os acidentes, os disfuncionamentos do dispositivo técnico. Desvios muito grandes poderão conduzir o operador a reorganizar a sua actividade. As consequências sobre os meios de produção estão relacionadas com as modalidades de utilização dos equipamentos ou das instalações. Estas são susceptíveis de conduzir a um desgaste mais rápido, a destruições acidentais com efeitos possíveis não só sobre o operador e sobre a produção, mas também sobre o envolvimento do posto de trabalho e, até mesmo, sobre a empresa.

47 A outra classe de consequências visa as condições internas, ou seja o operador, podendo situar-se na saúde e capacidade funcional, na competência, na experiência profissional e na satisfação e motivação no trabalho. Frequentemente a actividade de trabalho e as condições nas quais é realizada ameaçam temporária ou permanentemente a integridade física e psicológica do operador. Mas, como sublinham Guérin et al. (1991), as consequências da actividade de trabalho não são só negativas, na medida em que a própria actividade permite também a realização de projectos pessoais, o aumento da competência e experiência profissional. De qualquer modo, as consequências, positivas ou negativas, têm sempre reflexos na vida social e económica, na evolução da carreira, na formação e na garantia de emprego.

Todas estas consequências podem manifestar-se num prazo variável, constituindo objectos de interpretação diferente segundo os parceiros sociais, os serviços ou as funções desempenhadas pelos vários actores no sistema. Convém precisar que apesar de não se observarem traços negativos da actividade de trabalho, não significa poder caracterizar-se positivamente a situação. 


\section{Tarefa, actividade e seu agente na análise psicológica do trabalho}

"Para a psicologia, o trabalho é considerado como uma actividade" (Leplat, 1997, p. 4, tradução livre) e neste sentido "(...) a análise psicológica do trabalho é a análise da actividade em situação de trabalho." (id. p. 13, tradução livre). A actividade ocupa, assim, um lugar central na análise psicológica do trabalho. Mas, como vemos pelo título deste ponto "tarefa, actividade e seu agente ... » é necessário considerar ainda outras duas noções para analisar o trabalho, pois como diz o autor "analisar o trabalho, é analisar as relações complexas e dinâmicas entre estas três noções (...)." (id. p.14, tradução livre). Portanto a análise da actividade é uma análise complexa, envolvida numa multiplicidade de interacções.

Segundo Leplat ( $1997 ; 2000)$, o estudo da actividade pode ser considerado segundo duas perspectivas : a partir da tarefa e a partir do seu agente. No domínio da psicologia ergonómica e da própria ergonomia a primeira perspectiva tem sido privilegiada. No entanto, na sua opinião, a segunda apresenta também aspectos interessantes. Como sublinha o autor,

51 A ideia essencial é de que existe uma realidade dinâmica com três facetas, o agente, a tarefa e a actividade, que estão ligados por interacções complexas. A actividade depende do agente e da tarefa, e mais precisamente da relação entre eles. Mas a actividade modifica também o agente, a tarefa e suas relações. A complexidade da análise está relacionada com estas interdependências (1997, p. 6, tradução livre).

Não temos, portanto, como afirma o autor, três elementos estáticos, mas antes três elementos dinâmicos que se co-determinam mutuamente.

Vejamos então as duas perspectivas referidas por Leplat. O ponto de vista da tarefa prescrita (T) consiste muito formalmente em considerar a actividade (A) a partir das características da tarefa : $\mathrm{A}=\mathrm{f}(\mathrm{T})$. Nesta perspectiva o exame recairá no que o agente faz relativamente ao que deve fazer e às condições nas quais ele deve fazer. $O$ ponto de vista do agente (ou sujeito S) consiste formalmente em considerar a actividade (A) a partir das características desse agente : $\mathrm{A}=\mathrm{f}(\mathrm{S})$. É o ponto de vista adoptado durante muito tempo pela psicologia diferencial, visando estabelecer relações entre os traços mais ou menos estáveis do agente e os aspectos da sua actividade. Este ponto de vista, actualmente, tem vindo a ocupar terreno no seio da ergonomia e da psicologia ergonómica em virtude do interesse prestado às questões ligadas à formação e ao envelhecimento.

Estas duas perspectivas foram adoptadas ao longo da história da análise do trabalho. Considerá-las isoladamente, por uma questão de comodidade de análise, proporciona, como referido, uma visão redutora da realidade de trabalho. Tarefa e agente não são evidentemente independentes porque ambos se relacionam numa mesma actividade.

Concebemos igualmente que é por um processo de tipo dialéctico que progride a análise, um melhor conhecimento de cada termo provoca um melhor conhecimento dos outros e reciprocamente. Assim, um conhecimento aprofundado do agente ajuda a descobrir os traços pertinentes da tarefa para ele, e, inversamente, um conhecimento mais preciso da tarefa é revelador dos traços do agente que são implicados na sua actividade. (Leplat, 2000, p. 53, tradução livre). 

prescrita e de verificar se existe um modelo aceitável para definir a dinâmica que as relaciona. Os desvios são então julgados tomando como referência a tarefa e são entendidos de forma negativa, como sendo infracções às prescrições : $\mathrm{o}$ agente não fez $\mathrm{o}$ que deveria fazer. Mas se aceitarmos que o agente "retrabalhou" as prescrições, podemos encarar os desvios de outro modo : o agente realizou outra tarefa que não a prescrita e neste sentido os desvios não podem ser analisados tomando as prescrições como referência, mas sim essa outra tarefa. Esta concepção coloca enfoque na ideia de que não existe uma tarefa única, a prescrita, mas várias tarefas, inclusivamente elaboradas pelo próprio operador. "Diremos então que quando tomamos o ponto de vista da tarefa para analisar a actividade não será pois em acordar o primaz ao extrínseco, mas considerar a actividade como a elaboração, pelo sujeito, da sua tarefa." (Leplat, 1997, p. 16, tradução livre).

59 Para estudar a passagem da tarefa prescrita à actividade muitas vias são possíveis. Leplat (1997) propõe que se descreva a passagem em termos de múltiplas tarefas, mas alerta para o facto de, enquanto a execução tem uma componente observável (mesmo que comporte uma faceta inobservável), as tarefas intermédias têm antes um caracter hipotético e obrigam o analista à sua explicação (figura 2).

\subsubsection{Da tarefa a realizar à tarefa prescrita}

Como se pode depreender da figura 2, a passagem da tarefa a realizar à tarefa prescrita está directamente relacionada com a concepção. Trata-se, portanto, de uma transposição da intenção do conceptor numa descrição formal. Leplat (1997) faz corresponder a tarefa prescrita a um modelo da tarefa a realizar, modelo esse que se destina a um agente particular ou a uma classe determinada de agentes.

61 Contudo, em numerosas situações o conceptor apercebe-se que o resultado da execução da tarefa prescrita não corresponde ao que idealizou ou desejava obter. Tais desfasamentos podem ser reportados a dois aspectos. Por um lado é necessário considerar a coerência interna da própria descrição. Isto significa que a descrição tem que conter os elementos necessários de modo a ser traduzível na execução pretendida sem provocar confusões, nem contradições. Quando a tarefa a realizar é relativamente simples, torna-se fácil fazer uma descrição minuciosa dos objectivos e condições de realização (embora assim seja, não significa que todas as tarefas simples sejam devidamente explicitadas). Logo que a tarefa é mais complexa, torna-se difícil a sua 
descrição e, num caso extremo, pode mesmo ficar pelo objectivo geral (neste caso, como referimos, fala-se em missão). Por outro lado, a descrição tem ainda que estar adequada a quem efectivamente a vai realizar, ou seja, compreensível para aquele(s) a que se destina. 0 modelo da tarefa prescrita pressupõe um determinado modelo de agente, ou seja, um agente com determinadas características, com determinado nível de competência. No entanto, o modelo de agente estimado pelos conceptores pode efectivamente ter uma fraca correspondência com o agente real.

Figura 2 - Da tarefa a realizar à actividade descrita em termos de tarefa

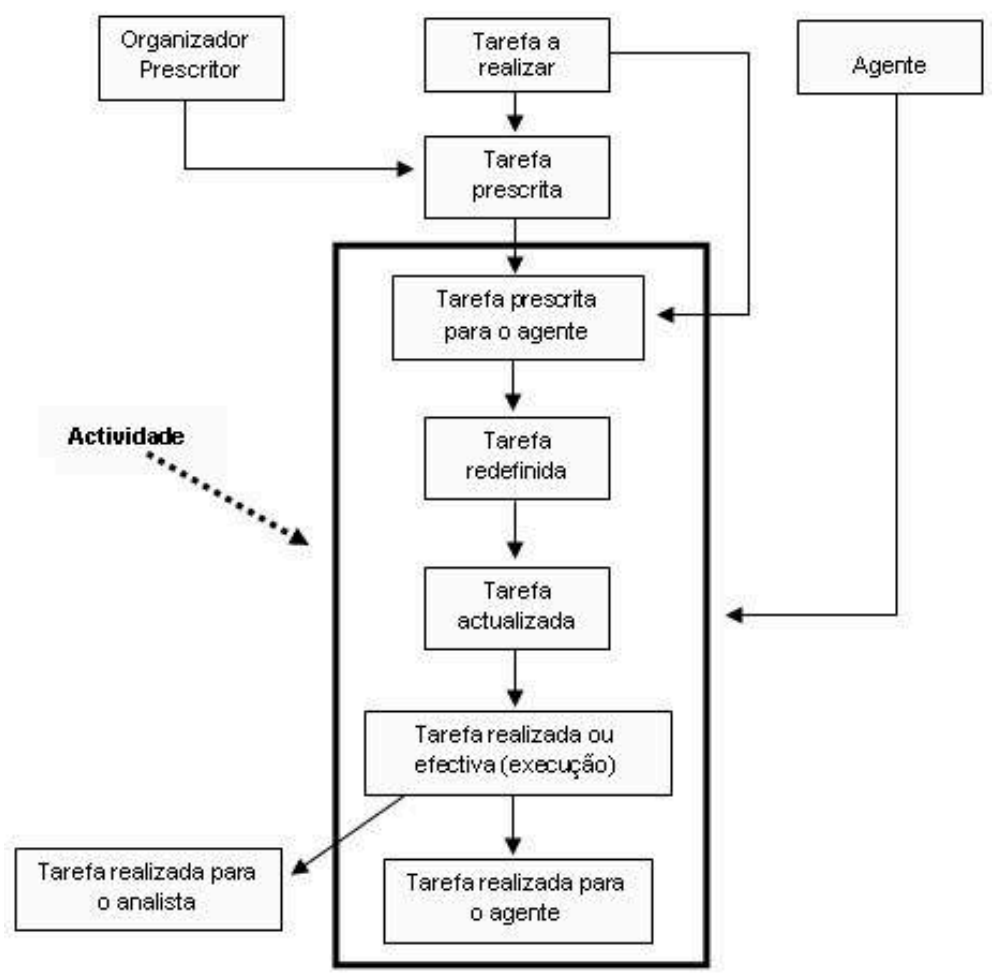

Ler a --> b como " b depende de a ». As setas de retorno ilustrando as interacções entre certas tarefas não foram mencionadas para não sobrecarregar a figura (in Leplat, 1997, p. 17).

\subsubsection{Da tarefa prescrita à actividade do agente}

A tarefa prescrita pelo conceptor é obrigatoriamente sujeita a um entendimento, a uma interpretação particular pelo agente. Entramos assim no nível da tarefa prescrita para o agente, como exibido na figura 2. Da leitura que faz das prescrições o agente poderá constatar a existência de imperfeições, de lacunas, de contradições e até de omissões. Impõe-se então redefinir as prescrições de modo a tornarem-se exequíveis ou operacionalizáveis. Falamos agora de uma outra tarefa, a tarefa redefinida (Leplat, 1997 ; Poyet, 1990), que tal como a prescrita pode ser descrita por um objectivo e suas condições de execução, com a diferença de que não são os definidos pelo prescritor, mas os efectivamente considerados pelo agente.

Portanto, a tarefa redefinida é construída pelo agente por apropriação e redefinição das prescrições, em função das suas representações, estratégias, adesão a critérios ou regras (Poyet, 1990). Os desvios entre a redefinição feita pelo agente e as prescrições do conceptor não têm que ter forçosamente um carácter negativo: de facto a tarefa 
redefinida pode "(...) completar e adaptar a tarefa prescrita e tornar assim o operador mais fiável (...).” (Fadier, 1994, p. 42, tradução livre).

Porém, a tarefa redefinida não deve ser entendida apenas como uma especificação da tarefa prescrita realizada pelo agente na medida em que o processo de redefinição se enraíza na história pessoal do próprio agente. Quer isto dizer que a redefinição da tarefa prescrita visa também atingir objectivos pessoais e sociais : a sua promoção, a sua carreira, a sua saúde física e mental, a sua integração no grupo, a construção da sua identidade, etc. (Clot, 1995 ; Dejours, 1995 ; Leplat, 1997). Isto significa que o agente procura não só responder à sua própria tarefa mas também considerar o impacto dessa resposta na actividade dos outros e reciprocamente.

As prescrições assumem, frequentemente, que o sistema produtivo apresenta um funcionamento regular. Ora os sistemas produtivos podem em determinadas circunstâncias apresentar-se instáveis ou até mesmo imprevisíveis: variações na quantidade e qualidade de matéria ou componentes, cortes de energia, desgastes de instrumentos e ferramentas por utilização, etc. Em tais circunstâncias a tarefa redefinida pelo agente, e que constitui a sua tarefa habitual, não é mais exequível. Impõe-se a tomada de precauções particulares, a aplicação de outros procedimentos, regras, critérios de êxito, recuperar incidentes ou disfuncionamentos.

66 A tarefa redefinida foi actualizada, isto é, adaptada em função das alterações ocorridas na situação. Poyet (1990) define esta tarefa actualizada como a contextuação, a particularização do modelo da tarefa para o agente em função das alterações e constrangimentos da situação. Esta actualização que se traduz numa variação adaptativa dos modos operatórios é normalmente transitória. Assumirá um carácter definitivo, e incluirá a redefinição da tarefa, caso as variações ocorridas forem admitidas como um constrangimento habitual do trabalho.

67 A tarefa redefinida ou actualizada vai dar lugar a uma execução sujeita à apreciação do próprio agente. Admite-se que a par de uma representação da sua tarefa, o agente interprete também a sua própria execução. É pela confrontação entre os resultados obtidos e os objectivos incluídos na tarefa redefinida que o agente avalia a necessidade de operar ou não regulações e decide os procedimentos necessários para as implementar.

São todas estas transformações, desde a apropriação das prescrições à execução e respectiva apreciação que constituem a actividade de trabalho. Justifica-se, assim, porquê a utilização única e simples da tarefa prescrita, para analisar a actividade, é falaciosa. Isto não significa que para a análise da actividade não seja importante o conhecimento da tarefa prescrita, mas somente que utilizá-la em exclusivo é manifestamente insuficiente. Aliás como refere Leplat (1997) “(...) o conhecimento dessa tarefa (considere-se prescrita) é uma das chaves do conhecimento da actividade" (p.23, tradução livre). Assim, actividade não pode ser inferida directamente do conhecimento da tarefa prescrita, mas esta pode dar uma contribuição importante à análise da actividade (Leplat \& Pailhous, 1977).

\subsubsection{A tarefa realizada para o analista}

69 Abordar a génese da actividade a partir da tarefa prescrita consiste em interrogar como o agente responde a essa tarefa, como ele a transforma, eventualmente em função das suas características e das suas próprias finalidades. Consiste em considerar que o 
trabalho cobre múltiplas dimensões, relações sociais, remunerações, carreiras, etc., que pesam naturalmente na actividade, não se limitando esta ao cumprimento de objectivos de produção.

Portanto, a actividade de trabalho do agente, é sujeita a uma leitura própria, singular, a uma representação por parte do analista (psicólogo, ergonomista). Isto significa que a actividade de trabalho do agente é construída ou reconstruída pelo analista, sendo esse processo também sujeito à influência dos seus saberes.

71 Ao resultado desta construção Leplat e Hoc (1983) designam de tarefa efectiva. Em termos gerais, podemos dizer que a tarefa efectiva corresponde ao modelo da actividade construído pelo analista. Contudo, como alertam os autores ela não é um “decalque» da parte observável da actividade, na medida em que, por exemplo, considera para a definição de um procedimento, derivado da observação de determinado comportamento, as regras de funcionamento cognitivo. Esta tarefa corresponde ao que efectivamente o agente faz e pode ser formalizada nos mesmos termos que a prescrita, com a diferença de que os objectivos e suas condições de execução são os efectivamente considerados pelo agente tal como o analista os depreende. Em resultado, só pode ser inferida pelo conhecimento integrado da actividade (considerando-a em termos de múltiplas tarefas) e da tarefa prescrita, associado a conhecimentos psicológicos e técnicos adquiridos por outras fontes.

Para Leplat e Hoc (1983), a validação do modelo que constitui a tarefa efectiva far-se-á pela confrontação das predições do modelo com os traços observáveis da actividade e, neste sentido, consideram a descrição da tarefa efectiva, realizada pelo analista como um ajustamento progressivo de um modelo à actividade.

\subsection{A análise da actividade a partir do agente}

73 No ponto anterior abordámos a análise da actividade segundo o ponto de vista da tarefa, sendo esta a visão mais clássica em psicologia ergonómica. Vamos agora abordar a análise da actividade centrada no agente.

O agente intervém de dois modos na actividade (Leplat, 1997 ; 2000) :

- Como sistema de tratamento da tarefa com as suas próprias características : competência, personalidade, recursos comportamentos, etc. A tarefa aqui figurará como "pivot", na medida que é em relação a ela que se definirão as características pertinentes do agente.

- Como ser humano que visa alcançar os seus próprios fins. Pela sua actividade o agente procura não somente responder à tarefa prescrita, como ainda, e ao mesmo tempo, realizarse, valorizar-se, adquirir um certo estatuto, ser reconhecido entre os seus pares, etc.

Nos pontos que se seguem abordaremos apenas sumariamente estas duas vertentes. Para maiores aprofundamentos aconselhamos a consulta das obras do próprio Leplat (1997; 2000) bem como do "Vocabulaire de l'ergonomie » de Montmollin (1995) onde, neste último se encontram reflexões interessantes dos conceitos subjacentes a estas duas vertentes.

\subsubsection{0 agente como sistema de tratamento da tarefa}

Para executar a tarefa o agente possui e utiliza um certo número de meios, instrumentos e recursos, não só inerentes à sua natureza, como também adquiridos no decurso da sua experiência ou mais geralmente da sua vida. Entre os “ instrumentos " 
encontram-se as ferramentas cognitivas de base e seu funcionamento (como por exemplo a memória), os conhecimentos, as competências, os metaconhecimentos, etc. Dispõe igualmente de recursos que correspondem à base energética do seu funcionamento. A quantidade de recursos disponibilizados para esse funcionamento representa a carga de trabalho específica, física ou mental. Acrescenta-se a tudo isto a personalidade do próprio indivíduo que lhe dará um determinado estilo cognitivo. Sobre esta perspectiva Leplat tem, principalmente, se debruçado sobre o conceito de competência onde registamos várias publicações $(1991 ; 1995 ; 2000)$.

\subsubsection{A actividade como meio do agente para alcançar os seus próprios fins}

77 Através da sua actividade o agente persegue uma outra categoria de fins que não lhe permitem somente alcançar os objectivos que lhe foram fixados : segundo Leplat (1997) “(...) ela (actividade) visa construir a sua identidade, fazer-se reconhecer pelos outros, exprimir certos valores, etc." (p.46, tradução livre). Esta faceta está patente no texto de Dejours (1995) quando afirma que "(...) trabalhar não é somente cumprir actos técnicos, é também fazer funcionar o tecido social e as dinâmicas intersubjectivas indispensáveis à psicodinâmica do reconhecimento (...)" (p.66, tradução livre).

Trata-se aqui, nesta perspectiva, de enquadrar as motivações, os valores do agente que apesar de lhe serem próprios são naturalmente influenciados pelas circunstâncias sociais de realização da actividade. Por exemplo, ao procurar melhorar as suas competências, o agente não visa apenas fazer face às exigências da tarefa, mas também se auto-valorizar, e com isso facilitar a sua integração social. Portanto, a aquisição e melhoria das competências torna-se um fim em si mesmo (Leplat, 2000).

Nesta perspectiva de análise, dois aspectos merecem serem evocados. O primeiro é as variações de comportamento do agente que, habitualmente, se relacionam com a tarefa ou com a carga de trabalho, mas que em certas circunstâncias têm uma origem lúdica : mudar, fazer de outro modo, encontrar uma nova solução, pelo único motivo de não fazer sempre a mesma coisa. Naturalmente que esta necessidade de mudança é sentida de forma diferente segundo os indivíduos. Assim, numa análise da actividade de trabalho é preciso estar atento à origem dessas variações. O segundo prende-se com as estratégias desenvolvidas no sentido de procurar preservar a sua saúde, a sua integridade física no decurso do exercício da sua actividade, limitando a ocorrência de agressões à sua saúde. A redefinição da tarefa, constitui uma forma, mais ou menos directa, de preservar a saúde e a integridade física, na medida em que nela se traduzem escolhas pessoais em termos de critérios de êxito, de aceitabilidade, adesão a determinadas regras de processo ou de segurança, etc. A regulação permanente da carga de trabalho (definir limites de aceitabilidade de carga, modificar os modos operatórios de forma a não ultrapassar os limites definidos), que não é independente da redefinição da própria tarefa, constitui igualmente um meio de minimizar o impacto das exigências da tarefa na sua saúde. $O$ agente pode ainda reflectir sobre o risco que representa para a sua saúde as condições em que exerce a sua actividade e procurar, mesmo sem ter sido obrigado, a proteger-se desses perigos. 


\section{Perspectivas metodológicas na análise psicológica da actividade}

80 A análise do trabalho esteve durante muito tempo, e quase exclusivamente, orientada para os trabalhos de predominância manual e dedicada à descrição dos aspectos observáveis, negligenciando ou relegando para segundo plano os aspectos cognitivos e perceptivos (Leplat, 1986). A proliferação de trabalhos de predominância mental, fruto da transformação técnica e tecnológica das condições de trabalho, associada aos aprofundamentos teóricos e experimentais do funcionamento cognitivo humano, contribuíram para que os aspectos mentais subjacentes à actividade de trabalho passassem desde a década de 1960 a constituir, também, objecto de estudo, em particular nas tarefas ditas complexas.

\subsection{Modalidades de estudo}

81 "A análise psicológica do trabalho visa essencialmente analisar os mecanismos postos em jogo em situação de trabalho" (Leplat, 1993b, p. 121, tradução livre). Leplat adverte que uma análise desta natureza não é, certamente, isenta de dificuldades: o funcionamento do sistema cognitivo é inobservável, o que se observa são apenas os comportamentos dele resultantes e os traços deixados pela sua execução.

Figura 3 As vias de acesso ao estudo da actividade (in Leplat, 1982a, p. 349).

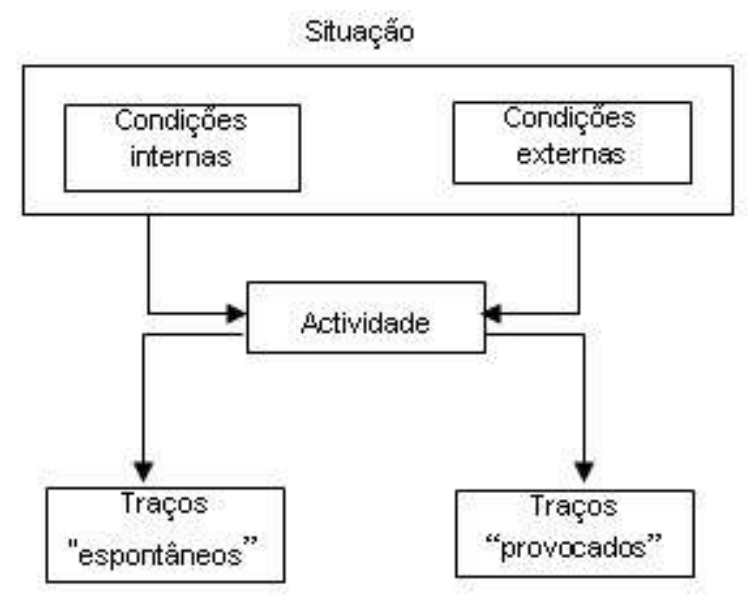

Leplat (1982a) considera que a actividade mental não pode ser conhecida senão através das suas manifestações ou traços observáveis (figura 3). Como vemos na figura 3, os traços podem ser espontâneos, ou seja decorrentes de uma realização autónoma pelo operador ou podem ser provocados, quando procuramos obter, sobre esta mesma actividade, informações que o operador não dá espontaneamente. $\mathrm{Na}$ primeira categoria incluem-se os dados relativos aos gestos, posturas, direcções do olhar, erros, comunicações; na segunda privilegiam-se as verbalizações, embora o recurso às representações gráficas seja também utilizado. $O$ contexto de recolha desses dados pode consistir na situação normal de trabalho ou recorrer-se à sua modificação de modo a tentar provar certas hipóteses. Estas modificações poderão ser introduzidas sistematicamente quando o analista tem essa possibilidade, ou poderá utilizar as mudanças que se produzem no meio. Estas modificações tocam quer as condições 
internas - características dos sujeitos - quer as externas por exemplo por modificação das regras de execução, das condições técnicas e materiais ou ainda pelo recurso à simulação.

Combinando estas duas vias de abordagem (traços espontâneos/provocados ; situação normal/modificada) chegamos a um modelo (figura 4), diferenciando quatro modalidades de estudo de utilização complementar, tendo em vista enriquecer, elaborar e verificar hipóteses sobre os mecanismos que regem a actividade.

Figura 4 Modalidades de estudo da actividade (in Leplat 1982a, p. 349)

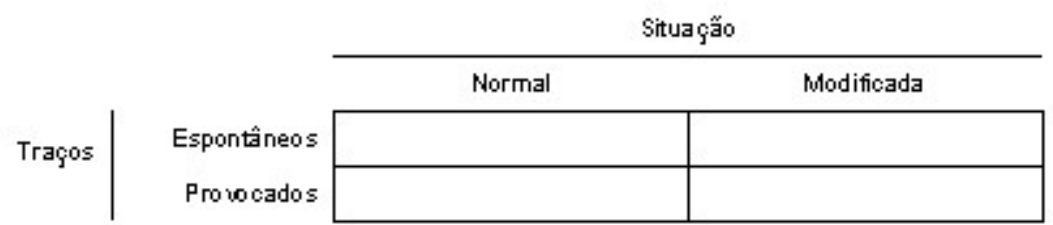

\subsection{Algumas técnicas de análise} 作 condições do estudo que vai ser realizado e de responder às suas questões. Por outro, permite recolher informações sobre as características gerais da situação de trabalho, tendo em vista compreender melhor o problema e elaborar as questões ou hipóteses provisórias que orientarão a pesquisa.

No que respeita à modalidade, as entrevistas poderão ser livres, ou obedecer a um plano preciso de questões. As limitações apontadas às entrevistas prendem-se com o facto de os sujeitos interrogados poderem ser mais ou menos capazes de exprimir os traços da sua actividade ou a dos outros. Assim, os dados da entrevista poderão ser considerados como não reflectindo fielmente a "realidade ». Esta limitação será retomada no ponto seguinte. 
O questionário constitui um prolongamento ou até mesmo um substituto da entrevista, contendo um conjunto de questões por vezes definidas a partir de entrevistas prévias. A sua vantagem face às entrevistas é o facto de permitir obter informações sobre uma grande população de uma maneira relativamente rápida e económica.

\subsubsection{A verbalização}

"Entrevista e a verbalização são ambas produções linguísticas muito semelhantes e cuja escolha de um ou de outro termo depende frequentemente das preferências. Nos estudos de orientação clínica encontramos frequentemente o termo entrevista. Nos de orientação experimental, o termo verbalização" (Leplat, 2000, p. 83, tradução livre). Segundo o autor a distinção entre ambas reside quer no carácter mais aberto da entrevista, uma vez que a verbalização responde a instruções mais precisas, quer no facto desta última incidir mais sobre a actividade do sujeito, enquanto que a entrevista pode abordar objectos diferentes. A verbalização distingue-se ainda da comunicação na medida em que, ao contrário desta, não faz parte da actividade de trabalho.

Para Rabardel et al. (1998) "as verbalizações são discursos do operador e, mais amplamente, das outras pessoas presentes na empresa, sobre a situação de trabalho e o seu trabalho." (p.141, tradução livre). Como refere Caverni (1988) estes discursos são proferidos em linguagem natural.

91 A utilização da verbalização para o estudo da actividade humana tem uma longa história no domínio da psicologia. Guérin et al. (1991) e Leplat (2000) indicam três razões pelas quais a verbalização é essencial no estudo da actividade de trabalho :

- A actividade não pode ser reduzida ao que é manifesto e portanto ao observável. Os raciocínios, o tratamento das informações, a planificação das acções, não podem ser verdadeiramente apreendidas senão através das explicações dos operadores (esta razão é a que se encontra mais próxima dos argumentos da psicologia cognitiva);

- As observações e medidas são sempre limitadas na sua duração. Assim, o operador pode ajudar a re-situar as observações num quadro temporal mais amplo ;

- As consequências do trabalho não são todas aparentes. A fadiga, eventuais problemas sentidos, podem não ter tradução manifesta e daí a utilidade de os operadores os exprimirem e colocarem em relação com as características da actividade. Estas razões são de carácter geral. Os argumentos de utilização da verbalização ao longo das diferentes fases de análise de uma situação de trabalho são, naturalmente, mais específicos e prendem-se com os objectivos de cada fase.

- Existem várias modalidades da verbalização, que segundo Leplat (2000) podemos classificar em função de diferentes critérios :

- Origem: a verbalização tanto pode ser espontânea como provocada pelo analista, ergonomista, psicólogo. No primeiro caso, trata-se de um discurso espontâneo, voluntário, do operador sobre o seu trabalho dirigido ao analista. No segundo caso, e é o mais frequentemente citado, a verbalização resulta de um questionamento do analista ao operador. Em ambos os casos o discurso proferido depende primeiro da relação de confiança que se estabelece entre ambos, segundo da compreensão do operador quanto ao estatuto e aos objectivos do analista, e por último da capacidade do próprio operador em explicitar o seu trabalho.

- Objecto : consiste naquilo que é solicitado ao operador verbalizar : (1) sobre uma execução particular, (2) sobre um procedimento, uma regra e suas condições; (3) sobre os 
conhecimentos subjacentes à actividade, no que respeita às propriedades do sistema técnico ; (4) sobre as suas intenções, expectativas, motivações, valores.

- Momento: considerando a execução propriamente dita, distinguem-se três tipos de verbalizações: (1) as prévias, que são verbalizações antecipadas face à execução ; (2) as simultâneas ou concomitantes, efectuadas no decurso do trabalho, e ; (3) as consecutivas, efectuadas após o trabalho. A escolha por uma ou por outra depende das condições de exercício da actividade de trabalho estudada e do tipo de informação procurada (Guérin et al. 1991), tendo todas elas, naturalmente, vantagens e inconvenientes. decurso do exercício dessa mesma actividade. Essa recolha obriga o psicólogo ou o ergonomista a uma presença no próprio local e durante a realização do trabalho. Como sublinham Guérin et al. (1991) "esta constatação “evidente" marca a diferença fundamental entre os métodos relativos à análise da actividade e outros modos de abordagem do trabalho." (p.170, tradução livre). Neste sentido, e como afirmam os autores a "abordagem mais imediata da actividade é a observação." (Guérin et al., 1991, p. 170, tradução livre) tendo um interesse particular no âmbito do estudo das actividades mentais, como justificam Leplat e Cuny (1983) e Weill-Fassina (1990). Os dados recolhidos por observação, deverão ser completados pelo recurso à verbalização, ou seja, procurando respostas a alguns “porquês » que vão surgindo da própria observação. "Observar é descobrir factos, acontecimentos, acções caracterizando uma situação que escolhemos privilegiar. Toda a observação é uma escolha guiada pelos princípios que podem ser muito diversos." (Leplat, 2000, p. 88). De facto, os dados saídos da observação não são tão inocentes quanto possam parecer. Tais dados correspondem a escolhas, ou preferências de acontecimentos entre aqueles que o observador percepciona, tendo em vista responder às questões que se colocam ou que a situação sugeriu pela representação que se tem dela (Guérin et al., 1991 ; Leplat, 2000). Trata-se, portanto, de um primeiro nível de redução que o analista realiza de forma consciente. É por isso que Leplat e Cuny (1983) afirmam que, (...) por mais rica que seja, não pode pretender ser exaustiva, sobretudo quando se trata de situações, tão complexas como o trabalho. Toda e qualquer observação é já uma selecção dos factos: constitui uma leitura da situação, entre muitas outras possíveis. Há sempre interesse em explicitar a natureza dessa leitura que, aliás, depende dos conhecimentos do observador e dos seus objectivos. (p.110, tradução livre).

tam-nos, por isso, para o facto de, como observadores, nos precavermos contra duas escolhas opostas : “(...) a pretensão ilusória e estéril de querer observar tudo e a observação demasiado parcial, exclusivamente dirigida por um hipótese, que poderia deixar escapar factos muito significativos para o estudo" (Leplat \& Cuny, 1983, p. 110, tradução livre). Depois de recolhidas essas notas torna-se necessário tratá-las, isto é, 
reorganizálas de forma a poder apreender o seu significado. Esta reorganização pode ser feita de múltiplas maneiras e em função do tipo de abordagem realizada, a sua leitura será certamente diferente, o que nos permite dizer que se realizou ai uma nova redução.

A observação é considerada menos " reactiva " que a entrevista e que a verbalização, no sentido em que o processo de análise interfere menos com a actividade. Concebe-se, contudo, que esta reactividade não é totalmente anulada uma vez que o trabalhador sabe que está a ser observado.

$\mathrm{Na}$ realização da sua actividade de trabalho o operador utiliza uma variedade importante de funções fisiológicas e psicológicas. Essas funções suportam a actividade observável, visível ao analista, isto é, os comportamentos. Assim, uma primeira ordem de observáveis (objectos da observação) é os comportamentos exteriorizados pelos operadores no decurso da realização da sua actividade de trabalho (as acções corporais, nomeadamente postura, deslocações, gestos, a direcção do olhar, as comunicações...). Outra ordem de observáveis é igualmente os comportamentos, mas característicos do próprio ofício que têm para o agente um significado particular e que habitualmente assumem designações intimamente relacionadas com o próprio ofício.

Leplat (2000) considera dois tipos de observação, a observação aberta e a observação sistemática. A primeira é de grande utilidade quando se inicia um estudo, permitindo ter uma visão geral do trabalho e definir melhor o problema que foi colocado. É a partir desta observação que se torna possível levantar questões mais precisas que orientarão progressivamente a análise e consequentemente a escolha de métodos de observação mais apurados. A observação sistemática visa recolher os factos e os acontecimentos precisos em resposta a questões igualmente precisas suscitadas normalmente pela observação aberta. Tratase, portanto, de uma abordagem mais precisa que tem por objectivo verificar as hipóteses emergentes da observação aberta e colocadas sob a designação de pré-diagnóstico.

Quanto aos modos de observação são apontados dois : observação instantânea e diferida ou assistida. A primeira tem por objectivo o registo directo e imediato do trabalho; a segunda recorre à ajuda de equipamentos como o vídeo e/ou o registador de acontecimentos.

Outros autores (Guérin et al., 1991) referem-se ainda quanto ao momento de observação : a observação contínua e observação instantânea para distinguir a tomada em consideração ou não, respectivamente, da continuidade temporal do trabalho. Assim, "instantâneo" emprega-se para designar a observação feita num determinado intervalo de tempo, ou em momentos significativos do trabalho. Por seu turno a observação contínua consiste na modalidade que acompanha todo o período de trabalho. Exige, por isso, a presença permanente do observador no local, acompanhando o desenrolar do trabalho. Em ambas pode-se recorrer a técnicas de registo que permitam uma análise em diferido.

100 Frequentemente são apontadas duas grandes limitações à observação da actividade de trabalho (Guérin et al., 1991) :

- Dificuldade de apreender a variabilidade existente nas situações de trabalho pela observação. A escala temporal de uma análise, forçosamente limitada, pode deixar escapar : (1) numerosos aspectos pertinentes que se manifestam em prazos mais longos; (2) as aleatoriedades incidentais ; 
- A actividade apreendida pelas suas manifestações observáveis. A observação é insuficiente para compreender os motivos dessa actividade, os raciocínios e os conhecimentos que a subentendem.

\subsubsection{A análise dos efeitos indesejados da actividade}


geralmente das condições externas da actividade, a outra visa a simulação dos sujeitos e mais especificamente dos processos cognitivos que estes colocam em acção na actividade (é a primeira que nos interessa aqui). A simulação também pode ser especificada em função da sua finalidade. Leplat (2000) distingue a simulação para pesquisa (investigação) visando melhorar o conhecimento da actividade, da simulação para formação visando melhorar a eficácia da própria actividade. "Simulação é a experimentação sobre um modelo [...] ela consiste em realizar uma reprodução artificial (modelo) do fenómeno que desejamos estudar, observar o comportamento dessa reprodução quando fazemos variar experimentalmente as acções que podemos exercer sobre ele, em induzir o que se passará na realidade sob a influência de acções análogas." (Encyclopaedia Universalis, in Leplat, 2000, p. 93, tradução livre). Segundo o autor (Leplat, 1997) o termo "modelo" indica que uma parte somente das características do fenómeno visado é retida. O simulador pode ser considerado como um modelo do sistema técnico simulado. Para o psicólogo, a relação entre esse modelo e o sistema simulado é definida em referência à actividade do operador.

A simulação de situações de trabalho visa responder a objectivos variados : de pesquisa, de formação, de concepção etc. Ela implica dois objectos (Leplat, 2000) : (1) uma situação a simular (ou situação de referência, já existente ou a criar) ; (2) uma situação que constitui uma simulação da precedente, dita situação de simulação.

Normalmente, na construção da situação de simulação é seguida uma abordagem ascendente, i.e. fundada sobre a análise de uma situação "natural ", acima referida como situação de referência, sua modelização, depois a elaboração de um dispositivo que reproduz alguns traços escolhidos como pertinentes. Entre a análise da situação de referência e a da situação de simulação existe uma dialéctica que as faz depender reciprocamente uma da outra e que se marca pela passagem de uma a outra no decurso de um estudo, com um enriquecimento do conhecimento de cada uma a cada passagem.

109 A cada uma daquelas situações é associável uma actividade. Como explica o autor (Leplat, 2000), avaliar a simulação consistirá em comparar a actividade da situação de simulação com a actividade da situação de referência ou a determinado aspecto dessa actividade que constituiu objecto de estudo.

110 O princípio de análise posto em prática pelo método de simulação consiste, geralmente, em fazer variar a situação de simulação para inferir dessas variações os mecanismos subjacentes à actividade. As variações podem visar as condições externas da execução da tarefa (objectivo, condições técnicas, regras, etc.) ou sobre as características do sujeito.

111 Leplat (2000) apresenta uma categorização das simulações em função de diversos critérios, estabelecidos a partir das relações entre situação de referência e situação construída, são eles : (1) as relações de escala entre situações que podem variar desde a simulação “plena escala " que constitui uma réplica muito próxima da situação de trabalho até simulações parciais que não reproduzem senão uma componente da situação; (2) o carácter dinâmico ou estático da simulação, correspondendo à possibilidade ou não, respectivamente, de a situação simulada evoluir no tempo ; (3) o carácter interactivo ou passivo das simulações dinâmicas, correspondendo à possibilidade ou não, respectivamente, do sujeito interagir sobre a situação simulada em tempo real ; (4) o objecto de simulação, podendo ser o sistema técnico ou o seu envolvimento 
112 Apesar de todo o interesse da simulação nas pesquisas em psicologia ergonómica Leplat (2000) alerta para o facto de ser "necessário não esquecer que uma situação simulada não é senão um modelo da situação de referência. Seja ele em plena escala, não coincide nunca com essa situação e a actividade do sujeito pode ser modificada por esses desvios." (p.98, tradução livre). Por isso, o autor avisa da necessidade de não transpor sem verificação, ou pelo menos sem precaução, as conclusões de um estudo de simulação para a situação de referência. $O$ autor apresenta cinco desvios típicos entre os dois tipos de situações: (1) o contexto de realização da actividade não é igual, na situação de referência é real na situação simulada é experimental ; (2) a actividade na situação de referência tem uma história, ao contrário da situação simulada ; (3) o valor do êxito e das falhas não tem o mesmo significado assumindo particular relevância em estudos no âmbito da segurança ; (4) variações na atitude dos operadores, na sua adesão e comprometimento face à situação real e aos cenários propostos, tendo relevância a relação estabelecida com o analista ; (5) o uso da simulação não visa senão uma duração reduzida, frequentemente ínfima, em relação ao tempo passado pelo operador na situação de trabalho. Esta " contracção do tempo " pode evidentemente ter efeitos que limitam a generalização dos resultados.

\section{Conclusão}

113 Este artigo dedicado ao trabalho de Jacques Leplat em torno da análise psicológica da actividade de trabalho está naturalmente incompleto. De facto, o autor não esgota os temas nos títulos aqui abordados. Porém, julgamos que o essencial das suas ideias foi aqui respeitado e sintetizado nestas breves páginas.

De tudo o que foi dito, situamos o contributo de Jacques Leplat em várias vertentes. A primeira na tentativa do autor de uma sistematização e clarificação de relações entre a psicologia do trabalho e a ergonomia. $O$ estabelecimento destas relações é importante no quadro não só de uma interdisciplinariedade de actores envolvidos nas intervenções, mas também de uma revisão do estatuto epistemológico de cada disciplina científica. $O$ desenvolvimento de um modelo-guia para a análise do trabalho constitui outro contributo de relevo. Este modelo formalizado na obra em co-autoria com Cuny datada 1983 (edição original em 1976 - note-se que já lá vão três décadas), afirmou-se na comunidade científica francófona de psicologia do trabalho e de ergonomia. Ainda que outros autores possam dar outro formato ao modelo, i.e. dandolhe outra organização, a essência, que podemos situar na sistematização de três níveis de análise condições, actividade e consequências - é uma constante na produção científica. Outra vertente da sua contribuição é a de situar diferentes perspectivas de análise da actividade : a partir da tarefa e a partir do agente. Embora a primeira perspectiva seja clássica em ergonomia e psicologia ergonómica, o caracter original dado pelo autor, está no modo como é encarada a actividade do sujeito: como elaboração de múltiplas tarefas. Esta visão confere ao sujeito a capacidade de transformar e redefinir a tarefa prescrita original em função das circunstâncias, modificando profundamente a leitura dos desvios entre tarefa e actividade. A segunda perspectiva, muito pouco clássica no domínio da ergonomia e da psicologia ergonómica, não deixa de ser interessante, embora alguns dos aspectos visados por ela sejam extremamente difíceis de por em relação com a actividade do sujeito. A terminar, referimo-nos ainda neste texto a uma outra vertente da contribuição de Leplat, os 
aspectos metodológicos em análise do trabalho. Esta temática foi desde sempre uma preocupação do autor, como atesta o vasto conjunto de obras e documentos publicados sobre ela. Aqui debruçámo-nos quase exclusivamente numa das muitas perspectivas com que o autor agarra este assunto : a de caracterizar algumas técnicas de análise do trabalho. É claro que este assunto particular, pela nossa parte, não ficou esgotado. Igualmente, outros assuntos desenvolvidos por Leplat, dentro do âmbito da metodologia em análise do trabalho, ficaram por apresentar.

115 Julgamos ter contribuído para um “ relance » de alguns aspectos da obra de Leplat. Para maiores aprofundamentos aconselhamos a consulta de textos originais não só de Leplat, mas também de outros autores, uns trabalhando directamente com ele, outros fonte de inspiração para o próprio Leplat.

\section{BIBLIOGRAFIA}

Amalberti, R. (1991). Introduction. In R. Amalberti, M. de Montmollin \& J. Theureau (Eds.), Modèles en analyse du travail (pp. 17-23). Liège : Mardaga.

Brehmer, B., Leplat J. \& Rasmussen, J. (1991). Use of simulation in the study of complex decision making. In J. Rasmussen, B. Brehmer \& J. Leplat (Eds.), Distributed Decision Making (pp. 373-386). Chichester, UK : Wiley.

Caverni, J.-P. (1988). La verbalisation comme source d'observables pour l'étude du fonctionnement cognitif. In J.-P. Caverni et al. (Eds.), Psychologie Cognitive, Modèles et Méthodes (pp. 253-273). Grenoble : Presses Universitaires de Grenoble.

Clot, Y. (1995). Le travail sans l'homme ? Pour une psychologie des milieux de travail et de vie. Paris : Éditions La Découverte.

Clot, Y. (1996). Psychologies du travail : une histoire possible. In Y. Clot (Ed.), Les histoires de la psychologie du travail. Approche pluridisciplinaire (pp. 1726). Toulouse : Octarès Éditions.

Dadoy M., Henty Cl., Hillau B., de Terssac G., Troussier J-F. \& Weill-Fassina A. (1990). Les analyses du travail. Enjeux et formes. Coll. des Etudes, 54. Paris : CEREQ.

Daniellou, F. (1996). L'ergonomie en quête de ses principes. Débats épistémologiques. Toulouse : Octarès Éditions.

Dejours, C. (1995). Le facteur humain. Paris : PUF.

Dessaigne, M.-F. \& Gaillard, I. (1997). Des évolutions en ergonomie. Toulouse : Octarès Éditions.

Fadier, E. (1994). L'état de l'art dans le domaine de la fiabilité humaine. Toulouse : Octarès Éditions.

Guérin, F., Laville, A., Daniellou, F., Duraffourg, J. \& Kerguelen, A. (1991). Comprendre le travail pour le transformer : la pratique de l'ergonomie. Montrouge : Editions ANACT.

Leplat, J. (1971-72). Planification de l'action et régulation d'un système complexe. In J. Leplat (1992) (Ed.), L'analyse du travail en psychologie ergonomique (pp. 87-97). Toulouse, Octarès Éditions. 
Leplat, J. (1972). La psychologie du travail en ergonomie. In M. Reuchlin (Ed.), Traité de psychologie appliquée (pp. 61-136). Paris : PUF.

Leplat, J. (1978). L'équivalence des situations de laboratoire et de terrain. Le Travail Humain, 41 (2), 307-318.

Leplat, J. (1980). La psychologie ergonomique. Paris : PUF.

Leplat, J. (1982). Le terrain, stimulant (ou obstacle) au développement de la psychologie cognitive. Cahiers de Psychologie Cognitive, 2, 115-130.

Leplat, J. (1982a). Perspectives méthodologiques pour l'étude des activités mentales. Le Travail Humain, 54 (2), 347-355.

Leplat, J. (1985). Erreur Humain, fiabilité humaine dans le travail. Paris : Armand Colin

Leplat, J. (1985a). Les représentations fonctionnelles dans le travail. In J. Leplat (1992) (Ed.),

L'analyse du travail en psychologie ergonomique (pp. 107-120). Toulouse : Octarès Éditions.

Leplat, J. (1986). L'analyse psychologique du travail. In J. Leplat (1992) (Ed.), L'analyse du travail en psychologie ergonomique (pp. 23-39). Toulouse : Octarès Éditions.

Leplat, J. (1988). Les habilités cognitives dans le travail. In P. Perruchet (Ed.), Les automatismes cognitifs (pp. 139-172). Liege :Mardaga.

Leplat, J. (1989). Error analysis, instrument and object of task analysis. Ergonomics, 32 (7), 813-822.

Leplat, J. (1990). Relations between task and activity : elements for elaborating a frame work for error analysis. Ergonomics, 33 (10/11), 1389-1402.

Leplat, J. (1990a) Skills and tacit skills : a psychological perspective. Applied Psychology : an International Review, 39, 143-154.

Leplat, J. (1991). Compétence et ergonomie. In R. Amalberti, M. de Montmollin \& J. Theureau (Eds.), Modèles en analyse du travail (pp. 263-278). Liege : Mardaga.

Leplat, J. (1991a). Organization of activity in collective task. In J. Rasmussen et al. (Eds.), Distributed decision making : cognitive models for cooperative work (pp. 51-73). Chichester : John Wiley \& Sons.

Leplat, J. (1992-3). L'analyse du travail en psychologie ergonomique. Tomes 1 e 2, Toulouse : Octarès Éditions.

Leplat, J. (1993). Intention et erreur : contribution à l'étude de la responsabilité. Revue Européenne de Psychologie Appliquée, 4, 279-287. Leplat, J. (1993a). Ergonomie et activités collectives. In F. Six, X. Vaxevanoglou (Eds.), Les aspects collectifs du travail (pp. 7-27). Toulouse : Octarès Éditions.

Leplat, J. (1993b). L'analyse psychologique du travail : quelques jalons historiques. Le Travail Humain, 56 (2-3), 115-131.

Leplat, J. (1994). Collective activity en work : some lines of research. Le Travail Humain, 57 (3), 209-227.

Leplat, J. (1995). A propos des compétences incorporées. Éducation Permanente, 123, 101-114.

Leplat, J. (1996). Présentation de la journée. In B. Cambon de Lavallete \& M. Neboit (Coord.). L'erreur humaine, question de points de vue? (pp. 3-10). Toulouse : Octarès Éditions. 
Leplat, J. (1997). Regards sur l'activité en situation de travail. Contributions à la psychologie ergonomique. Paris : PUF.

Leplat, J. (2000). L'analyse psychologique de l'activité en ergonomie. Aperçu sur son évolution, ses modèles et ses méthodes. Toulouse : Octarès Éditions.

Leplat, J. (2000a). Compétences individuelles, compétences collectives. Psychologie du Travail et des Organisations, 6 (3-4), 47-73.

Leplat, J. (2002). Psychologie de la formation. Jalons et perspectives. Choix de textes (1955-2002). Toulouse : Octarès Éditions.

Leplat, J. (2003). Questions autour de la notion de risque. In D.R. Kouabenan \& M. Dubois (Eds.), Les risques professionnels : évolutions des approches, nouvelles perspectives (pp 37-52). Toulouse : Octarès Éditions.

Leplat, J. \& Bisseret, A. (1965). Analyse des processus de traitement de l'information chez le contrôleur de la navigation aérienne. In J. Leplat (1993) (Ed.), L'analyse du travail en psychologie ergonomique (pp. 215-236). Toulouse : Octarès Éditions.

Leplat, J. \& Pailhous, J. (1977). La description de la tâche : Statut et rôle dans la résolution de problèmes. Bulletin de Psychologie, XXXI(332), 149-156.

Leplat, J. \& Cuny, X. (1979). Les accidents de travail. Paris : PUF.

Leplat, J. \& Cuny, X. (1983). Introdução à psicologia do trabalho. Lisboa : F.C.G.

Leplat, J. \& Hoc, J.M. (1981). Subsequent verbalization in the study of cognitive processes. Ergonomics, 24 (10), 743-755.

Leplat, J. \& Hoc, J.-M. (1983). Tâche et activité dans l'analyse psychologique des situations. In J. Leplat (1992) (Ed). L'analyse du travail en psychologie ergonomique (pp. 47-59). Toulouse : Octarès Éditions.

Leplat, J. \& Savoyant, A. (1984). Ordonnancement et coordination des activités dans les travaux individuels et collectifs. Bulletin de Psychologie, XXXVII(364), 271-279.

Leplat, J. \& Terssac, G. (1990) (Eds.). Les facteurs humains de la fiabilité dans les systèmes complexes. Toulouse : Octarès Éditions.

Monteau, M. ; Pham, D. (1987). L'accident du travail : évolution des conceptions. In C. LevyLeboyer \& J.-C. Spérandio (Eds.), Traité de psychologie du travail (pp. 703-726). Paris : PUF.

Montmollin, M. de (1986). L'intelligence de la tâche. Eléments d'ergonomie cognitive. Berne : Peter Lang.

Montmollin, M. de (1995). Vocabulaire de l'ergonomie. Toulouse : Octarès Éditions.

Ombredane, A. (1955). Analyse du travail. Facteur d'économie et de productivité. In J. Leplat (1992) (Ed.), L'analyse du travail en psychologie ergonomique (pp. 9-22). Toulouse : Octarès Éditions.

Ombredane, A. \& Faverge, J-M. (1955). L'analyse du travail. Paris : PUF.

Poyet (1990). L'homme, agent de fiabilité dans les systèmes automatisés. In J. Leplat \& G. Terssac (Eds.), Les facteurs humains de la fiabilité dans les systèmes complexes (pp. 223-240). Toulouse : Octarès Éditions.

Rabardel, P., Carlin, N., Chesnais, M., Llang, N., Joliff, G. \& Pascal, M. (1998). Ergonomie, concepts et méthodes. Toulouse : Octarès Éditions. 
Rasmussen, J., Duncan, K. \& Leplat, J. (1987). New technology and human error. Chichester : John Wiley \& Sons.

SELF (1997). Recherche, Pratique, Formation en Ergonomie. Evolutions et interactions dans le contexte social, économique et technique. Proccedings of XXXII Congrés de la Self, Lyon, França.

Weill-Fassina, A. (1990). L'analyse des aspects cognitifs du travail. In M. Dadoy et al. (Eds.), Les analyses du travail, enjeux et formes (pp. 193-198). Coll. des Etudes, 54, Paris : CEREQ.

Wisner, A. (1995). La constitution de problèmes, sa description para l'analyse ergonomique du travail. In A. Wisner (Ed.), Réflexions sur l'ergonomie (1962-1995) (pp. 129-140). Toulouse :

Octarès Éditions.

\section{NOTAS}

1. Apresentamos aqui o conceito de tecnologia exposto na sua obra mais recente "tecnologia é entendida aqui como a colocação em prática de conhecimentos para um fim determinado." (Leplat, 2000, p.3, tradução livre)

2. Este termo provém do verbo inglês "afford" que significa fornecer, oferecer, procurar e não tem tradução simples quer para francês quer para português. $O$ termo evoca as propriedades que os objectos apresentam, as quais determinam o modo como os objectos podem ser utilizados. Leplat (2000) sugere a consulta de outras fontes onde são apresentados exemplos.

\section{RESUMOS}

Pretendemos com este artigo apresentar, sumariamente, a concepção teórico-metodológica da psicologia ergonómica construída ao longo de várias décadas pelo Professor Jacques Leplat. Organizámos a presente síntese em três partes. Na primeira parte fazemos uma apresentação geral das concepções de Leplat relativas à psicologia ergonómica e suas relações com a ergonomia, traçamos de seguida as relações e especificidades da análise psicológica da actividade e da análise ergonómica do trabalho e terminamos com um modelo-guia de análise, amplamente difundido nas obras do autor. Na segunda parte iremos centrar-nos em duas perspectivas de análise da actividade : a análise centrada na tarefa e a análise centrada no seu agente, o operador. $\mathrm{Na}$ terceira parte iremos situar-nos nas propriedades, benefícios e limitações dos métodos utilizados nessa análise.

Queremos presentar sumariamente, con este artículo, el diseño teórico-metodológico de la psicología ergonómica construida a lo largo de varias décadas por el Profesor Jacques Leplat. Hemos organizado esta síntesis en tres partes. En la primera parte hacemos una presentación general de los diseños de Leplat relativos a la psicología ergonómica y su relación con la ergonomía, a continuación trazamos la relación y especificidades del análisis psicológico de la actividad y del análisis ergonómico del trabajo y terminamos con un modelo-guía de análisis, ampliamente difundido en las obras del autor. En la segunda parte nos centraremos en dos perspectivas de análisis de la actividad : el análisis centrado en la tarea y el análisis centrado en 
su agente, el operador. En la tercera parte nos situaremos en las propiedades, beneficios y limitaciones de algunos métodos utilizados en ese análisis.

L'objectif de cet article est de présenter, de façon synthétique, la conception théoricométhodologique de la psychologie ergonomique telle que l'a construite le Professeur Jacques Leplat au long de plusieurs décennies. Nous avons organisé ce texte en trois parties. Dans la première, nous privilégions une présentation générale des conceptions de Leplat concernant la psychologie ergonomique et ses relations avec l'ergonomie. Nous y situons les spécificités de l'analyse psychologique de l'activité et de l'analyse ergonomique du travail en recourant, pour conclure, au modèle d'analyse que l'on retrouve dans plusieurs œuvres de l'auteur. Dans le seconde partie, nous mettons en évidence deux perspectives d'analyse de l'activité : celle qui est centrée sur la tâche et celle qui analyse davantage son agent, l'opérateur. Dans la troisième partie, nous reprenons les propriétés, dans leurs apports et leurs limites, des quelques méthodes utilisées dans le cadre de ces analyses.

We intend with this article to concisely present the theoreticalmethodological conception of ergonomic psychology constructed along various decades by Professor Jacques Leplat. We organized the present synthesis in three parts. In the first part we make a general presentation of the Leplat conceptions about ergonomic psychology and its relation with ergonomics; design the relations and specificities of the psychological analysis of activity and the ergonomic analysis of work; and end with an analysis model, broadly disseminated in the author's texts. In the second part we focus on two perspectives of activity analysis : analysis focused on the task and analysis focused on its agent, the operator. In the third part we develop the properties, benefits and limitations of similar methods used in this analysis.

\section{ÍNDICE}

Keywords: ergonomic psychology, psychological analysis of work, task, activity, methods Palavras-chave: psicologia ergonómica, análise psicológica do trabalho, tarefa, actividade, métodos

Palabras claves: psicología ergonómica, análisis psicológico del trabajo, tarea, actividad, métodos

Mots-clés: psychologie ergonomique, analyse psychologique du travail, tâche, activité, méthodes

\section{AUTOR}

\section{CATARINA SILVA}

Faculdade de Motricidade, Humana Estrada da Costa, Dafundo, 1495 - 688 Lisboa Portugal csilva@fmh.utl.pt 